\title{
LOS ESTUDIOS CTS Y LA NUEVA ESTRATEGIA DE LA
} EDUCACIÓN SUPERIOR LATINOAMERICANA.

Nereyda Moya y Juana María Brito*

RESUMEN:

A propósito de un loable empeño de la OEI, en torno a la formación de especialistas de todas las áreas en una educación humanista y en valores, sobre Ciencia, Tecnología y Sociedad, a través de la creación en el contex to Iberoamericano de las Cátedras CTS + I (Ciencia, Tecnologia, Sociedad + Innovación), nuestro trabajo refleja las diferentes relaciones que se pueden establecer entre esta perspectiva $u$ orientación sobre el desarrollo tecnocientífico y la estrategia que se desarrolla en las universidades latinoamericanas en la formación de los profesionales.

Se inicia comparando las estrategias del Banco Mundial (BM) y de la UNESCO en torno al papel de las Universidades, expone las nuevas imágenes que estos estudios proponen sobre Ciencia y Tecnología y valora el significado de los Estudios CTS para las Universidades.

Palabras Claves:

Educación Superior, ciencia, tecnología, sociedad, innovación.

\section{Dos enfoques SObre la Problemática de la EduCación SUPERIOR LATINOAMERICANA.}

Desde la década de los 60 se produce un debate en torno a las funciones y el papel social de la Educación Superior, debate que coincide con las políticas de desarrollo económico sostenidas para América Latina.

() Universidad de Cienfuegos - Cuba 
Treinta años después, en los años 90, el debate centra su atención en el cuestionamiento acerca de la eficacia de la Educación Superior, sobre la base de su rendimiento económico y social así como de las inversiones que a ella se destinan.

Los temas esenciales del debate giran en torno a:

a) Los objetivos de la Educación superior frente al nuevo milenio.

b) El papel de las ciencias sociales en el análisis de la problemática mundial.

c) La integración de la docencia y la investigación.

d) Las formas de alcanzar la democratización y la calidad de la Educación Superior.

e) La diversificación de los sistemas de la Educación Superior y el vínculo Universidad - Empresa.

f) El papel de la Educación Permanente en la enseñanza superior.

g) La independencia intelectual y académica.

h) El impacto de la Globalización

i) Situación del financiamiento. ${ }^{[1]}$

Estos temas han sido analizados desde dos direcciones totalmente contrapuestas por dos organizaciones de carácter internacional: el BM y la UNESCO, conformando los dos enfoques acerca de la situación de la Educación Superior, en los países en desarrollo.

La visión que aporta el $\mathrm{BM}$, es eminentemente economicista, reconoce la importancia de la Educación Superior para el desarrollo económico social así como su papel en el proceso del conocimiento científico, revela aquellas limitaciones que han marcado el proceso de enseñanza universitario como: poca eficiencia en la utilización de los recursos, pocos graduados con baja calidad y a un alto costo. 
Estos elementos lo llevan a concluir que la asignación de recursos financieros debe dirigirse a niveles de enseñanza inferiores, que según el $\mathrm{BM}$, contribuyen más a la equidad social. Al mismo tiempo plantean una estrategia de reforma que constituye un serio peligro para la Educación Superior en la región, especialmente para el sector público.

La calidad, la respuesta adecuada de la Educación Superior al mercado cambiante y la equidad constituyen el objetivo de la reforma planteada, pero los propios elementos en que se fundamenta la estrategia son un boomerang para el sector universitario, ya que muchos directivos se pliegan al BM para lograr financiamiento, en detrimento de las funciones sociales básicas que debe cumplir la Educación Superior Latinoamericana.

En fin, el BM ve a la Educación Superior como parte del problema del desarrollo Latinoamericano proponiendo disminuir los recursos para estos fines. ${ }^{[2]}$

La otra visión de la problemática la aporta la UNESCO, organización especializada de la ONU que plantea dentro de sus misiones la colaboración, el acercamiento y la paz entre las naciones desde las esferas de la Educación, la Ciencia y la Cultura.

En 1995, luego de una amplia consulta sobre el tema, publica el documento contrapartida al de el BM, denominado Documento sobre Politicas para el Cambio y el Desarrollo de la Educación Superior en el que se señala:

“...estamos presenciando un desarrollo sin precedentes de la Educación Superior y una mayor conciencia acerca de su papel vital en el desarrollo económico y social" [3]

Este criterio se justifica en las serias transformaciones ocurridas en el sector de la Educación Superior, determinados por un contexto económico, político y social que a escala regional ha cambiado considerablemente en las dos últimas décadas. 
La universidad latinoamericana enfrenta hoy la necesidad de impulsar su desarrollo y con ello contribuir decisivamente al desarrollo de los sistemas de ciencia y tecnología, como parte de su función creativa.

El documento elaborado por la UNESCO, fundamenta las tendencias principales y los desafíos que enfrenta la Educación Superior ante el nuevo milenio, destacando tres tendencias fundamentales:

\section{a) Expansión Cuantitativa.}

La Educación Superior en Latinoamérica aunque no ha logrado cambios cuantitativos a la escala con que se opera en los países desarrollados que en las dos últimas décadas alcanzaron aumentar un $13.1 \%(27.1 \%$ a $40.2 \%)$, logra un cierto incremento ya que en América Latina y otros países en desarrollo el crecimiento fue de un $4 \%(10.1 \%$ a $14.1 \%){ }^{[4]}$

La enseñanza superior en Latinoamérica deja de ser una actividad elitista para convertirse en una actividad de masas, a pesar del crecimiento disparejo que se observa a escala global y regional.

De 1980 a 1990, 13 países aumentan el número de estudiantes en la Educación Superior y se destacan entre ellos El Salvador, Cuba, Perú, Argentina y Uruguay. (Véase Informe Mundial sobre la Ciencia 1996)

El crecimiento cuantitativo se aprecia claramente en las cifras de matricula total que en 1960 era de 270,000 estudiantes universitarios y en 1990 alcanza 8 millones. ${ }^{[5]}$

b) Diversificación de las estructuras institucionales, los programas y las formas de estudio.

Este factor interno del cambio de las instituciones de Educación Superior tiene su fundamento en los saltos que se producen en los conocimientos que obligan a estructurar en la inter- 
disciplinariedad como alternativa de integración del conocimiento, es decir, una visión integrada del objeto a escala teórica.

Unido a esto se dan nuevas formas de gobierno y administración de las IES, se acotan la misión y visión de los centros en función de su contexto.

Existe además una variada tipología de instituciones de acuerdo a la duración de los estudios, el perfil académico, las formas de enseñanza, las fuentes de financiamiento. Se trabaja por el autogobierno basado en relaciones de libertad académica y autonomía institucional. Las relaciones de la Universidad con el estado deben velar por el cumplimiento de estos dos principios. El presupuesto que le aporta el Estado en muchos casos disminuye como consecuencia directa de la crisis, lo que se manifiesta en la tendencia que se explica a continuación:

\section{c) Restricción financiera.}

La Universidad Latinoamericana en general tiene el financiamiento como eje alrededor del cual se mueven los problemas que hoy presenta su calidad. De ahí que le corresponde buscar fuertes alternativas de financiamiento y administrar adecuadamente los recursos humanos y materiales. Las serias restricciones financieras son un mal que aqueja hoy a todo el sector de la Educación Superior en la región.

En el Informe Mundial sobre la Ciencia 1996 se reflejan los gastos en Educación en 1980 y 1990, de los 14 países analizados. Nueve de ellos (Bolivia, Chile, Costa Rica, Cuba, Ecuador, El Salvador, Guatemala, México y Venezuela) evidencian un importante descenso en estos gastos, producto de la situación general de crisis de los años 80 , que sólo ahora en los 90 se comienza a remontar. (Véase Informe Mundial sobre la Ciencia, 1996)

Si se conjugan el aumento en las matrículas y las serias restricciones financieras a las que se encuentra sometida la Univer- 
sidad Latinoamericana, se puede concluir en relación a las limitaciones que esto implica en cuanto a la calidad.

En general, estas tendencias no son más que una expresión del entorno científico, económico, social, cultural y político de la región muy común a todos los países del área. La llamada década perdida redujo el PIB a cifras obtenidas en los finales de la década del 60. El atraso industrial, la dependencia económica y política, la falta de una infraestructura técnica y científica son factores que han sumido a la Educación y en especial a la Educación Superior en una situación crítica.

Estas realidades determinan que la UNESCO empeñada en lograr una sustentabilidad social a diferencia del BM, contribuya a la toma de conciencia de la necesidad que supone la Educación superior para alcanzar el desarrollo de la región, en un mundo marcado por procesos globalizadores.

Tres criterios esenciales propone entonces para la Universidad el Documento sobre Políticas para el Cambio y el Desarrollo de la Educación Superior, los que deben regirla en este mundo que se transforma incesantemente, planteando así la nueva visión de las respuestas de la Educación Superior:

- Pertinencia.

- Calidad.

- Internacionalización.

Por su lugar en el proceso de cambio que aspira a lograr nuestra región, desde diferentes puntos de vistas y programas políticos, la calidad es el eje central de la nueva visión de la Universidad Latinoamericana, es el elemento que determina la satisfacción de las necesidades y las expectativas que suscitan; calidad en su personal docente, en sus programas, en la infraestructura y medio universitario y en los estudiantes.

La calidad determina por tanto su pertinencia, es decir, su puesto y cometido en la sociedad, ya que implica dar respuesta a 
sus funciones con respecto a los servicios generales que deben afectar y a la formación de graduados con sólidos conocimientos y habilidades suficientes para interactuar adecuadamente en relación a las necesidades y a lo que espera la sociedad. La calidad permite la pertinencia, que " tiene relación directa con las expectativas y sensaciones de la sociedad con la Universidad ", al mismo tiempo la calidad incide en la internacionalización que debe basarse en la asociación y la búsqueda colectiva de la calidad.

La calidad es la medida de la pertinencia pues solo allí de donde sale un egresado capaz de enfrentar los retos sociales del mundo contemporáneo se asume el criterio que la institución ha cumplido su rol.

Las profundas transformaciones operadas en los sistemas de la producción de bienes y servicios comercializables han ensanchado la importancia estratégica de la investigación científica y la necesidad de vincular los recursos humanos creativos con empresarios emprendedores.

Todo esto sitúa en el centro del proceso a la investigación que beneficia la calidad de la enseñanza y vincula estrechamente a la Universidad y el sector productivo en la actual tendencia a la innovación.

Esta visión de la Universidad conduce al nuevo criterio de la "Universidad Dinámica", que puede resumirse en los siguientes aspectos esenciales:

- Un lugar de formación de alta calidad, eficiente, eficaz y con amplitud de funciones, tanto cívicas, como profesionales, al que se accede por la capacidad intelectual.

- Comunidad dedicada a la investigación, la creación y la difusión del conocimiento, el progreso de la Ciencia y que participe en la innovación e invención tecnólógica.

- Calidad del conocimiento, basado en el principio de Educación Permanente. 
- Una comunidad basada en la cooperación con la industria y los servicios a favor del progreśo económico de la región y la nación.

- Una comunidad que oferte a los ciudadanos y a los expertos una información científica fiable.

- Una comunidad que forme a sus estudiantes en principios cívicos, de paz y justicia social, y bien ubicada en las condiciones de su entorno social, mundial, regional y local. ${ }^{[6]}$

II. Los Estudios CTS. Significación En la NUEVA ESTRATEgia UNIVERSITARIA.

Paralelamente al debate sobre la Educación Superior en los países en desarrollo y en América Latina en particular, en los años 60 los países desarrollados realizan una profunda revisión de la imagen tradicional que se mantenía en torno a Ciencia y Tecnología, así como su papel en la vida social.

¿Qué factores determinaron esta revisión?

1. El alcance social de los impactos que la ciencia y la tecnología han tenido desde la segunda mitad de este siglo y que se hacen más evidentes en la fase industrial. Esto las convierte en objeto de debate social y político, consolidándose una serie de movimientos de protesta (grupos contraculturales, asociaciones estudiantiles, organizaciones ecologistas o pacifistas, etc.)

2. El movimiento académico de los estudios de CTS que aporta una visión del conocimiento científico radicalmente distinta e incompatible con las tradicionales imágenes.

Varias direcciones han tenido los estudios y programas que conforman este movimiento CTS: 
- Campo investigativo: reflexión alternativa a la tradicional concepción académica sobre Ciencia y tecnología.

- Campo de la política: promoción de una activa participación pública en la gestión y evaluación de la Ciencia y la Tecnología.

- Campo de la educación: aparición de nuevos programas interdisciplinarios de enseñanza, tanto de secundaria como universitaria.

Los estudios CTS son la respuesta de la comunidad académica a la creciente insatisfacción con la concepción tradicional de Ciencia y tecnología, a los problemas políticos y económicos relacionados con el desarrollo científico-tecnológico. ${ }^{[5]}$

Uno de los principales campos de la investigación académica de este movimiento es el educativo, ya que promueve una transformación de las estructuras y contenidos educativos sobre la base de una nueva imagen de la ciencia y la tecnología en el contexto social.

Los estudios CTS sirven de fundamento por tanto a la nueva visión que desde la política humanista plantea la UNESCO, explicitando una nueva visión de la Universidad Latinoamericana.

La pertinencia, la calidad y el proceso de cooperación o internacionalización no pueden lograrse al margen del desarrollo científico y tecnológico. El por qué y el para qué de estos elementos se interrelacionan con la ciencia y la tecnología en la actualidad.

La calidad que es a nuestro juicio el eje de los otros dos elementos, es multidimensional y demanda una permanente evaluación institucional.

Ahora bien ¿podemos hablar de calidad de la Educación Superior al margen del desarrollo científico y tecnológico? Lógicamente no. Los estudios CTS promueven una organización 
curricular que determinan cambios metodológicos, didácticos y actitudinales, lo que implica una reformulación de objetivos, métodos y procedimientos.

Estas transformaciones tienen por base la propia estructura interdisciplinaria que como tendencia mantiene hoy la Educación Superior, interdependencia que caracteriza al conocimiento científico.

El proceso de relación entre las disciplinas "integración horizontal", consiste en un entrecruzamiento de las disciplinas tradicionales, que descansan en la unidad material del mundo, en la relación de estructuras objetivas que constituyen el objeto de las disciplinas.

La interdisciplinariedad no puede forzarse, ni es algo abstracto. A escala social los fenómenos de la cultura, la ciencia, la economía, la política y la ideología se articulan cada vez más como parte de un tejido social del mundo contemporáneo globalizado, contexto en el que coexiste la Universidad.

Los conocimientos científicos hoy día, se vuelven obsolescentes de forma prematura, los significativos impactos tecnológicos de la informática y la comunicación deben asumirse desde la perspectiva CTS, con sus riesgos y beneficios. No se puede brindar al estudiante universitario una visión parcializada, no los podemos convertir en fanáticos (pro-tecnologias) ni en catastrofistas (contra-tecnología).

La cultura informática es hoy una necesidad indiscutible de la enseñanza superior latinoamericana pero al mismo tiempo es un freno para el desarrollo de su calidad por la restricción financiera que limita el acceso a las tecnologías de punta.

¿Desde qué imagen se puede lograr la cultura científico tecnológica que espera la sociedad y que conforman la pertinencia de la Educación Superior? 
Ciencia y tecnología no pueden visualizarse desde una imagen tradicional sino desde una imagen totalmente desacralizadora, es decir, ciencia y tecnología como procesos sociales. Por lo que resulta significativo establecer las siguientes distinciones:

Desde el paradigma CTS, la ciencia es una actividad social ligada a la producción, aplicación y difusión de conocimientos, con lo que se desborda el marco tradicional, como se puede apreciar.

IMÁGENES DE LA CIENCIA

\begin{tabular}{|l|l|}
\hline \multicolumn{1}{|c|}{ TRADICIONAL } & \multicolumn{1}{c|}{ C.T.S. } \\
\hline $\begin{array}{l}\text { Aporta un ideal clásico } \\
\text { de la ciencia como: }\end{array}$ & Además de los \\
- Sistema de Conocimiento & incluye: \\
en desarrollo que debe & - Carácter histórico \\
corresponderse con la & Concreto. \\
verdad como ley. & - Forma de la Conciencia \\
- Aplicación Sistemática de & social. \\
métodos. & - Fuerza productiva Directa. \\
- Formulación de & - Actividad social. \\
Problemas científicos & - Institución social. \\
(hipótesis, conformación & \\
de teorías, etc.). & \\
- Acumulación de & \\
Conocimientos. & \\
\hline
\end{tabular}

En correspondencia con lo que aspira la UNESCO, los estudios CTS aportan una imagen más humanista y real sobre la Ciencia y la Tecnología, que incluye valores. Es una alternativa más loable y comprensible que permitirá formar a los ciudadanos que integran la pirámide de Ciencia y Tecnología del Estado. 
IMÁGENES DE LA TECNOLOGÍA

\begin{tabular}{|c|c|}
\hline TRADICIONAL & C. T. S. \\
\hline $\begin{array}{l}\text { Imagen artefactual: } \\
\text { - Concepción } \\
\text { Instrumentalista, visión } \\
\text { más arraigada a escala } \\
\text { cotidiana. Las tecnologias } \\
\text { son herramientas o } \\
\text { artefactos construidos } \\
\text { para una diversidad de } \\
\text { tareas. Solo refiere el } \\
\text { aspecto técnico. } \\
\text { Imagen Intelectualista: } \\
\text { - Tecnología es ciencia } \\
\text { aplicada, es un } \\
\text { conocimiento práctico } \\
\text { que se deriva de la } \\
\text { ciencia. }\end{array}$ & $\begin{array}{l}\text { Forma de organización } \\
\text { social integrada en socio- } \\
\text { sistema a su vez más } \\
\text { amplio e inter- } \\
\text { dependientes con tres } \\
\text { dimensiones: } \\
\text { - Dimensión técnica. } \\
\text { - Dimensión organizativa. } \\
\text { - Dimensión ideológica } \\
\text { cultural. }{ }^{[6]}\end{array}$ \\
\hline
\end{tabular}

Estos ciudadanos requieren de conocimientos científicos básicos, lo que es una necesidad universal ya que todos los ciudadanos participan de una $\mathrm{u}$ otra forma en la toma de decisiones sobre política científica y tecnológica.

Los estudios CTS, orientan desde una perspectiva mucho más flexible las principales finalidades de la investigación y la tecnología, lo que garantizaría que la universidad logre una alta calidad en la profesionalidad del trabajo que se realiza en estas esferas.

El Informe Mundial sobre la Ciencia 1996 reconoce 5 grandes grupos de categorías de funciones que deben desempeñar los profesionales en esta esfera: 
a) Producción de conocimientos científicos y tecnológicos básicos.

b) Formación. La universidad es la que contribuye directamente a ello, ya que a través de la investigación se garantiza la calidad en la formación de profesionales.

c) Producción de conocimientos y competencias necesarios para la política del sector público.

d) La contribución a los programas estratégicos del Estado.

e) La participación en la innovación industrial. [7]

Pero estos elementos no pueden prescindir de lo que Luján y López denominan el "Silogismo CTS" en el ámbito educativo y que propone:

"La innovación y el desarrollo científico tecnológico es una resultante social de factores culturales, políticos y económicos, por lo que son accesibles al no experto.

La política científico tecnológica es un factor determinante que modela nuestras formas de vida constituyendo un asunto público de primera magnitud.

Compartimos un compromiso democrático básico. Debemos promocionar la evaluación y control social del desarrollo científico tecnológico." ${ }^{[8]}$

Otro elemento importante en que incide el enfoque CTS en la nueva estrategia de la Universidad Latinoamericana, es en lo relativo a la separación que se produce entre las ciencias técnicas, naturales y las ciencias sociales y humanísticas.

El denominado "mito de las dos culturas" queda superado en la misma medida en que desde esta dirección se integran los conocimientos científicos.

La modernidad produjo la especialización y provocó una separación que solo conduce al empobrecimiento del conocimiento científico en general. 
Todos los factores contribuyen a ello, las instituciones de Educación Superior se hiperespecializan, separando los perfiles en detrimento de la resultante, el conocimiento. De la misma manera que en los profesionales de las ciencias naturales y técnicas se insiste en la formación de habilidades prácticas, en ellos se deben educar valores y profundizar sus conocimientos humanísticos.

La visión unilateral de la tecnología como artefacto o como ciencia aplicada conduce a entenderla como autónoma, evadiendo la responsabilidad de los científicos que la generan, por lo que no es una imagen ideal para formar en ella a los futuros profesionales.

El movimiento CTS, brinda una posición muy clara en torno a ética, ética de la ciencia, como la ética del científico.

El ETHOS propugnado por Merton ,y que conformó en su tiempo un nuevo campo de acción sociológico, es hoy un punto de partida esencial para los profesionales de la ciencia y en especial, para los investigadores universitarios de Latinoamérica, ya que es en la universidades latinoamericanas donde se concentra el mayor por ciento de las investigaciones de la región.

Una breve reflexión final, nos permite destacar que en las condiciones de hoy en Latinoamérica, el movimiento CTS no ha alcanzado la fuerza necesaria en las ciencias sociales, comienza a incluirse en los programas y cursos de postgrado y a insertarse en el pregrado.

Para el nuevo milenio, constituirán una necesidad la difusión y dominio por los especialistas y profesionales y las imágenes que sobre ciencia y tecnología en él se exponen, lo que será una importante contribución al desarrollo científico tecnológico de la región.

Tal y como plantea el Informe Mundial sobre la Ciencia 1996: 
"El diseño y la implementación de las estrategias de desarrollo que reclaman los paises de la región demandan la participación concertada de los gobiernos, del sector Ciencia y Tecnología, del sector productivo y de otros sectores sociales." [11]

Esta idea final del informe reafirma el "Silogismo CTS" y fundamenta la importancia de los Estudios CTS, en tantos promotores de la nueva imagen de la ciencia y la Tecnología, que involucra a todos los ciudadanos en tanto participantes directos del desarrollo científico tecnológico.

\section{CITAS Y REFERENCIAS.}

[1] Tunnermann Bernheim, Carlos. "Una nueva visión de la educación superior". En: Educación Superior y Sociedad. Vol. 6 N. ${ }^{\circ} 1$ p. 124

[2] Ibidem, p. 125-127.

[3] Yarzábal, Luis. La transformación universitaria en visperas del tercer milenio. CRESALC - UNESCO, Caracas, 1996. p. 7.

[4] Ibidem p.3

[5] Tunnermann. Op. cit, p 130.

[6] Ibidem p.135

[7] Gottifredi, Juan Carlos. "La pertinencia de la Educación Superior". En: La transformación universitaria en visperas del tercer milenio. CRESALC UNESCO. Caracas, 1996, p.13

[8] González García, Martha. Ciencia, Tecnologia y Sociedad. Editorial Tecnos S.A. Madrid 1996, p. 66.

[9] Acevedo Díaz, J. A. "La Tecnología en las relaciones CTS. Una aproximación al tema". En: Enseñanza de las ciencias. Vol. 14, 1995, p. 36.

[10] Papón, Pierre. "Los sistemas de ciencia y tecnología: panorama mundial." En: Informe Mundial sobre la Ciencia 1996. París. Ediciones UNESCO, pp. 9-2.

[11] Luján López, José L. "Educación CTS en acción. Enseñanza Secundadria y Universidad". En: Ciencia, Tecnología y Sociedad.p. 227 . 


\section{OTRA BIBLIOGRAFÍA CONSULTADA}

Ayala, Francisco. "Conocimientos científicos básicos". En: Informe Mundial sobre la Ciencia 1996. París: Ediciones UNESCO, p.1 - 5.

2 Núñez Jóver, Jorge. "Ciencia, Tecnología y Sociedad". En: Problemas sociales de la Ciencia y la Tecnología. GESOCYT. La Habana 1994. Editorial Félix Varela, pp. 83-96.

3 Núñez Jóver, Jorge. "La ciencia y la tecnología como procesos sociales". Material impreso. 1998. pp. 1-23. 